\title{
Solitary gastric metastasis from a renal cell carcino- ma, presenting 23 years after radical nephrectomy
}

A 65-year-old man presented to our department for evaluation of a gastric mass. His medical history revealed that he had undergone left nephrectomy for a renal cell carcinoma (RCC) 23 years earlier. Abdominal computed tomography (CT) revealed a strongly enhancing, well-defined, $2.5-\mathrm{cm}$ diameter mass in the stomach ( Fig. 1). Esophagogastroduodenoscopy (EGD) showed a $2.5-\mathrm{cm}$, polypoid lesion in the upper part of the body of the stomach ( Fig. 2).

A clinical diagnosis of gastric metastasis from the RCC was made. There was no evidence of further metastatic lesions in other organs, so the patient underwent a wedge resection of the gastric wall. Gross examination of the resected specimen revealed a round tumor that measured $2.5 \times 2.0 \times 1.5 \mathrm{~cm}$ ( Fig.3). Histopathology demonstrated a metastatic, clear celltype RCC, which was confined to the mucosa and submucosa ( Fig.4). The patient is alive, with no signs of disease recurrence 2 months after the operation. The stomach is an unusual site for metastasis even in autopsy studies, with a reported incidence of only $0.2 \%-0.7 \%$ [1, 2]. This case confirms the potential of RCC for late and solitary metastasis to the stomach. Although gastric metastases may be recognizable as abnormalities on EGD, their morphology is variable and there is no characteristic appearance that defines metastatic disease [1]. To the best of our knowledge, this is only the seventh case of a solitary gastric metastasis from RCC to be reported in the English literature [1-5]. From these cases, the median patient age was 67 (range 58-78), the median tumor size was $2 \mathrm{~cm}$ (range $1-5 \mathrm{~cm}$ ), and the median duration between the initial operation and the appearance of the gastric metastasis was 10 years (range 1 23 years). All the patients were treated by surgical resection. One patient died from liver metastases 5 months later. For patients with a solitary gastric metastasis from RCC, surgical resection has been the preferred choice of treatment.

Endoscopy_UCTN_Code_CCL_1AB_2AD_3AB

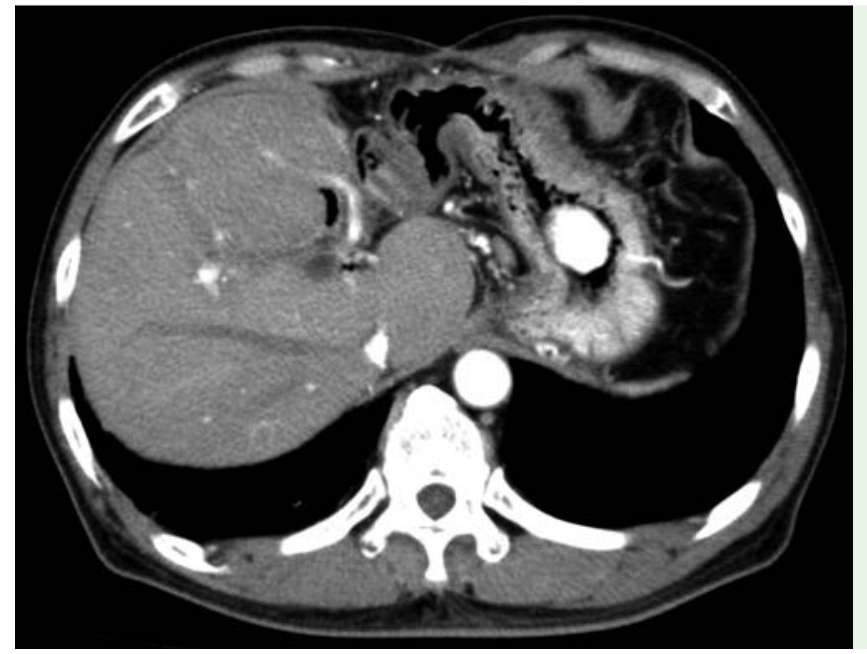

Fig. 1 Abdominal computed tomography (CT) scan showing a 2.5-cm mass in the stomach, which demonstrated strong enhancement after intravenous administration of contrast material.

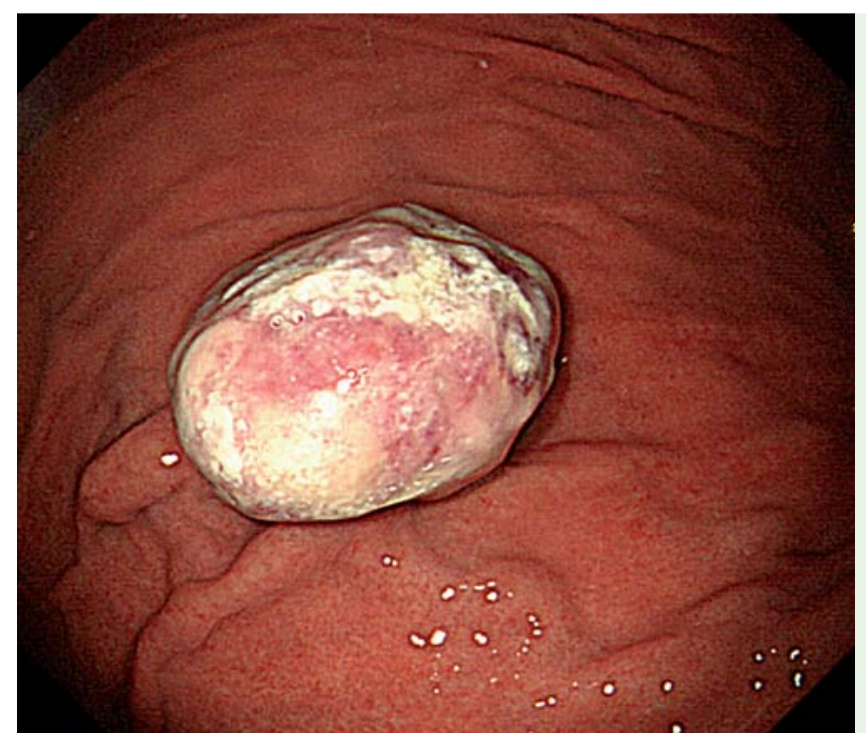

Fig. 2 Esophagogastroduodenoscopy (EGD) showing a well-circumscribed, polypoid lesion in the upper part of the body of the stomach.

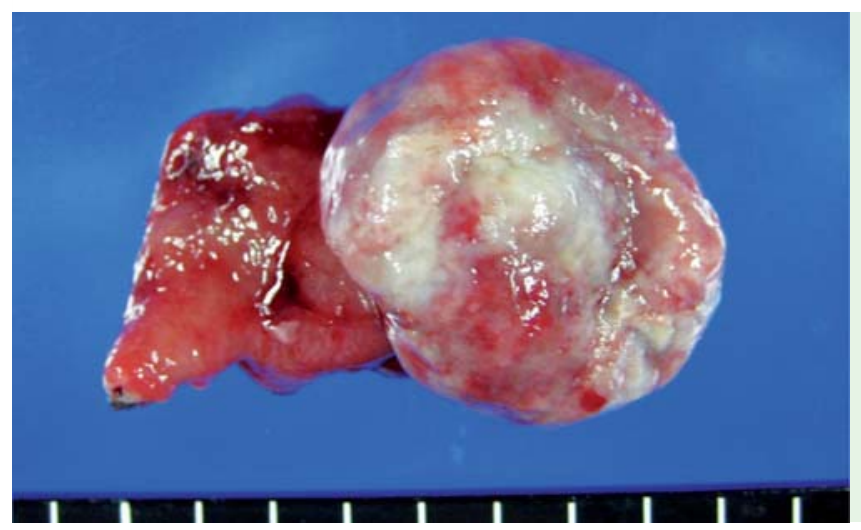

Fig. 3 Macroscopic appearance of the resected specimen showing a polypoid mass with a nodulated surface.

\section{Competing interests: None}




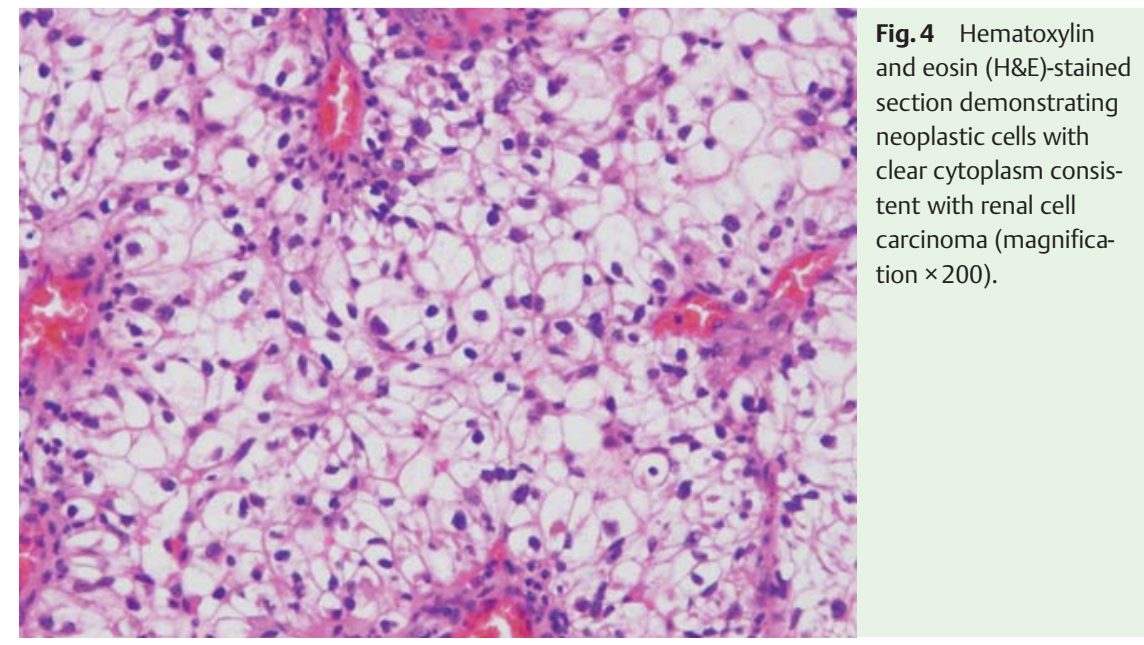

\section{T. Namikawa', J. Iwabu' ${ }^{1}$, H. Kitagawa' ${ }^{1}$, T. Okabayashi', M. Kobayashi², K. Hanazaki ${ }^{1}$}

${ }^{1}$ Department of Surgery, Kochi Medical School, Nankoku, Japan

2 Department of Human Health and Medical Sciences, Kochi Medical School, Nankoku, Japan
3 Sullivan WG, Cabot EB, Donohue RE. Metastatic renal cell carcinoma to stomach. Urology 1980; 15 : $375-378$

4 Odori T, Tsuboi Y, Katoh $K$ et al. A solitary hematogenous metastasis to the gastric wall from renal cell carcinoma four years after radical nephrectomy. J Clin Gastroenterol 1998; 26: 153-154

5 Saidi RF, Remine SG. Isolated gastric metastasis from renal cell carcinoma 10 years after radical nephrectomy. J Gastroenterol Hepatol 2007; 22: $143-144$

\section{Bibliography}

DOI http://dx.doi.org/

10.1055/s-0031-1291751

Endoscopy 2012; 44: E177-E178

(C) Georg Thieme Verlag KG

Stuttgart · New York

ISSN 0013-726X

\section{Corresponding author}

\section{T. Namikawa, MD, PhD}

Department of Surgery

Kochi Medical School

Kohasu, Oko-cho, Nankoku

Kochi 783-8505

Japan

Fax: +81-88-880-2371

tsutomun@kochi-u.ac.jp 